\title{
Review
}

\section{Da Costa's syndrome or neurocirculatory asthenia}

\author{
OGLESBY PAUL
}

From the Brigham and Women's Hospital, Harvard Medical School, Boston, Massachusetts, USA

SUMMARY The syndrome variously called Da Costa's syndrome, effort syndrome, neurocirculatory asthenia, etc has been studied for more than 100 years by many distinguished physicians. Originally identified in men in wartime, it has been widely recognised as a common chronic condition in both sexes in civilian life. Although the symptoms may seem to appear after infections and various physical and psychological stresses, neurocirculatory asthenia is most often encountered as a familial disorder that is unrelated to these factors, although they may aggravate an existing tendency. Respiratory complaints (including breathlessness, with and without effort, and smothering sensations) are almost universal, and palpitation, chest discomfort, dizziness and faintness, and fatigue are common. The physical examination is normal. The aetiology is obscure but patients usually have a normal life span. Reassurance and measures to improve physical fitness are helpful.

Da Costa's syndrome or neurocirculatory asthenia has a long and honourable history in the medical literature and in clinical medicine. Yet it is infrequently mentioned today. It is unlikely to have disappeared; it probably exists much as before but is more often identified and labelled in psychiatric terms such as "anxiety state" or "anxiety neurosis". There is no harm in this shift in diagnostic labels as long as the essential importance of the syndrome, its prognosis, and treatment are properly appreciated. Such is not always the case and, as in other medical issues, it is educational to review and summarise the past. What has been forgotten should not necessarily remain forgotten.

For the purposes of this discussion, a broad definition of $\mathrm{Da}$ Costa's syndrome that is applicable to military and civilian patients is: a disorder of unknown origin, often familial, characterised by the presence of one or more symptoms including breathlessness with and without effort, palpitation, nervousness, chest discomfort not typical of angina pectoris caused by ischaemic heart disease, fatigability, and faintness; tending to occur in attacks which may recur over years and for which there is no specific treatment.

Requests for reprints to Dr Oglesby Paul, Countway Library of Medicine, Harvard Medical School, 10 Shattuck Street, Boston, MA 02115, USA.

Accepted for publication 19 May 1987
Although Jacob M Da Costa is the name most honoured by history in this condition, at least one other relevant report antedated his paper in 1871. On 3 June 1863 Dr Henry Hartshorne made a presentation regarding heart disease in the Union Army to the College of Physicians in Philadelphia. He commented: "Among the chronic affections of soldiers, which are best studied in hospitals remote from the field, is one which does not seem to have met, as yet, with full appreciation by medical officers, inspectors and pension surgeons... The affection to which I allude may be designated as muscular exhaustion of the heart."1

Dr Hartshorne went on to mention that Dr Alfred Stille had delivered an address on a somewhat similar disorder, referred to by him as "palpitation", before the Philadelphia County Medical Society four months earlier. ${ }^{2}$ Stille had noted that this palpitation was "a very frequent symptom among the soldiers, occurring in perhaps every case of intercostal neuralgia, but often, also, originating apparently in a state of extreme exhaustion..." Hartshorne described how in an 80 bed ward of a Union army hospital over a seven month period the majority of the cardiac patients exhibited neither hypertrophy nor dilatation, or palpitation "from sympathy with irritated stomach, from nervousness, abuse of tobacco, etc", but cardiac muscular exhaustion. This was demonstrated by shortness of breath after moderate exertion and a rapid pulse on slight effort. The men appeared well and there were no 
cardiac murmurs; however, sometimes the first heart sound was diminished. Although there was improvement with several months of rest this did not cure most of the cases. He considered that the process was attributable to the stress of the military campaigns with "great and prolonged exertion with the most unfavorable conditions possible-privation of rest, deficient food, bad water, and malaria."

Four year later in February 1867, Dr W C Maclean, who was Professor of Military Medicine at the British Army Medical School, wrote a lecture entitled "Diseases of the heart in the British Army", which was published in the British Medical Journal. ${ }^{3}$ His message regarding British soldiers was different from that of Hartshorne because he was calling attention to cardiac hypertrophy and dilatation caused, he considered, by excessive exertion from carrying the soldier's field pack, which amounted to over 60 pounds, and by the manner in which its straps constricted the circulation. No symptoms are described in Maclean's paper and it hardly belongs in this historical sequence started by Hartshorne, although both were concerned with the role of physical exhaustion.

The first major publication on the topic was entitled "On irritable heart: a clinical study of a form of functional cardiac disorder and its consequences" by Dr Jacob M Da Costa, published in the January 1871 issue of the American Journal of Medical Sciences. ${ }^{4} \mathrm{Da}$ Costa was only one of a series of notable physicians to be intrigued by this problem, which over the next $\mathbf{7 0}$ years included some of the great names in internal medicine.

$\mathrm{Da}$ Costa was born in 1833 on the Island of St Thomas in the West Indies. He was educated in Europe and came to Philadelphia in 1849, where at the age of 16 he entered Jefferson Medical College. He graduated three years later at 19 and went on to enrich his education with 18 months of observation in the clinics of Paris and Vienna before returning to practise in Philadelphia. Wooley reviewed his distinguished career, ${ }^{5}$ which included publication in 1864 , when $\mathrm{Da}$ Costa was only aged 31 , of a volume on medical diagnosis which was so successful that it ran to nine editions and was translated into German, Russian, and French. Da Costa was appointed to the position of Chairman of Medicine at Jefferson Medical College, was elected President of the College of Physicians of Philadelphia, and was selected as one of the original members and later president of the Association of American Physicians.

$\mathrm{Da}$ Costa's role in military medicine came during the Civil War when Philadelphia became the site of several military hospitals. Da Costa was assigned to one at a suburban Philadelphia estate on Turner's Lane. Here Da Costa was exposed to a "cardiac mal- ady common among soldiers". He wrote a report about it to the War Department as early as December 1862 and finally summarised his thoughts in the 36 page article published in 1871 in the American Journal of Medical Sciences. ${ }^{4}$

Da Costa's clear description of this malady was supplemented by several case histories. Although the story he tells related only to soldiers, he made the point in the first paragraph that "Much of what I am about to say I could duplicate from the experience of private practice." Therefore, this was not a phenomenon seen solely in military surroundings. Later in the article he confirmed this by mentioning that some of his patients had experienced typical symptoms before enlisting. After commenting that he had chosen the name of "irritable heart" for this "peculiar form of functional disorder", which he believed had also occurred in British troops earlier in the century, he made the following observations.

The condition often followed a period of hard service in the field or a febrile illness with or without diarrhoea; less frequently it was seen after various situations including battle wounds and scurvy. The main symptoms were palpitation with a rapid pulse, with and without effort, and on occasion with slight irregularities; chest pain near the cardiac apex either sharp and lancinating, or dull in character, coming with and without effort; and shortness of breath, again not necessarily associated with exertion. A range of digestive complaints was also common. The physical examination was described as not remarkable except for the unusually rapid pulse, a quick cardiac impulse, and sometimes apical systolic murmurs. Treatment was prolonged and included rest and digitalis preparations, at times combined with aconite or other drugs. A few patients could return to full duty when they had completely recovered, but most had to be assigned light duty or were retired from the service. Da Costa made the point that one infrequent outcome was the development of cardiac hypertrophy, which he believed to have developed in 28 of 200 cases seen. Finally, he cautioned that such a condition occurs with "severe or protracted" military campaigns, and he urged adequate physical training for new recruits, avoidance of forced marches, and provision for adequate convalescence for those with acute infections before they returned to duty.

Such were the features of $\mathrm{Da}$ Costa's syndrome as set out in 1871. It must be borne in mind that on the one hand, some of the patients indeed did have or had had malaria, typhoid, acute gastroenteritis, scurvy, malnutrition, and physical exhaustion, and had a reason for temporary asthenia, and $\mathrm{Da}$ Costa considered these in his description. And on the other hand, a few others may have had organic heart dis- 
ease that was undiagnosable at the time, including coronary or hypertensive heart disease, myocarditis, and myocardiopathy. Rheumatic and syphilitic heart disease would probably have been diagnosed. Discounting these, there was left a vivid picture of a residual group with $\mathrm{Da}$ Costa's "cardiac malady" which is something else apart-an entity of uncertain origin, consistent clinical features, and disabling but not life threatening consequences.

Although the next major contributions in this area came during the first world war, there were minor evidences of interest from time to time in intervening years. The British authorities did alter the weight and strappings of the soldiers' packs and later altered training drills in futile attempts to prevent the problem from occurring in the troops. (Howell has recently written an excellent review of the British military experience with this syndrome. ${ }^{6}$ ) The condition is said to have been encountered during military operations in South Africa and India.

The first world war saw an amazing degree of concern for the syndrome described by Da Costa. Some of the best medical brains in Britain were recruited to study the problem. The reason for the mobilisation of all this scientific talent was the extent of $\mathrm{Da}$ Costa's syndrome in the allied military forces, which became apparent during the first months of the war. Alfred E Cohn wrote that as of 31 August 1918, 41699 men had been discharged from the British Army because of heart disease, "most of them probably" because of $\mathrm{Da}$ Costa's syndrome. The German army seems to have had a similar experience. Goldscheider reported to the Medical Society of Berlin in 1915 on the frequency in the troops of symptoms referable to the heart due to muscular and nervous exhaustion. ${ }^{8}$ He cited no statistics. In 1916 Archives des Maladies du Coeur contained a review of 23 published reports of cardiac problems in wartime, many of which resembled $\mathrm{Da}$ Costa's syndrome; 10 of the articles cited were German. ${ }^{9}$

As early as 1915, the British Medical Research Committee had arranged for study of "disorders of the soldier's heart" under the general direction of Sir James Mackenzie at University College Hospital in London. Later, an advisory committee was appointed including Mackenzie, Sir Clifford Allbutt, and Sir William Osler. Dr Thomas Lewis was put in charge of the undertaking; and he, T F Cotton, and F $\mathrm{H}$ Thiele made a brief report on the problem in the British Medical Journal in November 1915. ${ }^{10}$ Early in 1916 the Director-General of the Army Medical Service set aside the 250 bed Mount Vernon Hospital in Hampstead, London, for further investigation and rehabilitative treatment of the condition; late in 1917 the activities were transferred to a 700 bed hospital at Colchester in Essex. Other smaller rehabilitation centres were opened in other areas in 1918. British physicians assigned at the outset to Hampstead included John Parkinson, J C Meakins, and $\mathbf{R} M$ Wilson.

Six physicians from the United States (Samuel A Levine, Rufus A Morrison, Dr B S Oppenheimer, Marcus A Rothschild, William St Lawrence, and Frank N Wilson) who were experienced in cardiology were assigned in the summer of 1917 to Colchester by the Surgeon General of the United States Army on the advice of Dr Alfred E Cohn. Later, in 1918, the Surgeon General set aside 200 beds at the United States General Hospital No 9 at Lakewood, New Jersey, for the same purpose. These were under the direction of Dr Francis W Peabody. On 6 June 1918 the hospital was made a centre for cardiovascular disease. The medical officers there included Harry D Clough, Cyrus C Sturgis, and Joseph T Wearn.

One consequence of this heightened activity was a spate of new labels. Hartshorne had used the term "muscular exhaustion of the heart" in 1864, Da Costa had preferred "irritable heart" in 1871, Sir James Mackenzie used the label "general exhaustion" in 1916, ${ }^{11}$ Thomas Lewis used "effort syndrome" in his 1919 monograph, ${ }^{12}$ and the American workers preferred "neurocirculatory asthenia." 13 A vague wastebasket term, "disordered action of the heart", had also been used in the British Army, and the equally unsatisfactory term "soldier's heart" was used. In addition, the British army had the category "valvular disease of the heart", but in his series Lewis reported that 161 of 277 patients with this designation should be reclassified as "effort syndrome." 12

The most active and the earliest interest in $\mathrm{Da}$ Costa's syndrome during this period came from British workers under Thomas Lewis who was the newest bright star in the cardiac firmament and a remarkable investigator. ${ }^{14}$ Starting first at University College Hospital in London and then at the military hospitals in Hampstead and Colchester, Lewis and his team conducted a series of studies that resulted in more than 20 published papers.

Sir James Mackenzie who was a leading member of this group summarised his views of the syndrome as seen in British soldiers in a report published in the British Medical Journal in January $1916 .{ }^{11} \mathrm{He}$ found that a history of recent infections was present in most cases, and emphasised that fatigue and exhaustion were always present, and breathlessness was frequent. Depression and concern about heart disease was common, as were signs of vasomotor instability of the hands. In a 1920 article in the same journal, he wrote: "In a careful inquiry into the ori- 
gin of ill health in over 2,000 soldiers I found that in the case of about 80 per cent, the first onset of their illness began with some complaint of an infectious nature... In a number of cases there was no history of infection, and the onset of the illness seemed to be due to a variety of circumstances ... want of rest had evidently been the provoking agent in these instances." 15

Another early publication from the group was that of Parkinson, ${ }^{14}$ who described in 1916 his experience with 90 "cardiac" cases passing through a casualty clearing station in the British Expeditionary Force in France in the period March 1915 to January $1916 .{ }^{16} \mathrm{He}$ considered that 40 of these had "soldier's heart". Thirty nine of them complained of shortness of breath on exertion, 24 had precordial pain on effort (usually an ache that became sharper with increased exertion), 16 stated they were easily exhausted, and on auscultation nine had a short apical systolic murmur. After an average follow up of seven months, only nine were back on full duty and 17 were on light duty. He suggested that the "relative cardiac inefficiency" must represent the effects of previous infection, aging changes in men over 40 , or a constitutional endowment of a heart "with limited efficiency".

A characteristic case cited was that of a 22 year old private. "Since age of 17 , palpitation and shortness of breath on exertion. Light bench-work. September 1914 , enlisted. Same symptoms on doubling or hurrying. September 1915 to France. Palpitation, shortness of breath, exhaustion and dull pain in fourth to sixth left spaces about nipple line, all on marching. After one month admitted. Examination: no abnormal physical findings. Eight months later: full duty in France but no better."

The group with Thomas Lewis reported other observations on these soldiers. Firstly, with test exercise they became more symptomatic than control subjects; they were able to do less physically than the controls, and their pulse rates and systolic pressures rose more than those of the presumed normal soldiers. ${ }^{17}$ Second, there was no appreciable cardiac enlargement on orthodiographic measurement. ${ }^{18}$ Third, they seemed to have a slightly reduced vital capacity. ${ }^{19}$ Fourth, the men might show hyperalgesia in the precordial area. ${ }^{20}$ Fifth, although in 1916 they reported that the "cause of breathlessness is absence of an adequate supply of buffer salts in the blood," 21 a later (1919) study showed no clear reduction in the alkaline reserve of the blood. ${ }^{22}$ Sixth, symptoms were not improved by the administration of digitalis. ${ }^{23}$ Seventh, when given atropine, pilocarpine, and amyl nitrite they did not behave very differently from the control group. ${ }^{24-26}$ Eighth, they did not develop distinctive changes in the PR intervals with and after effort. ${ }^{27}$ Ninth, as described by Oppenheimer and Rothschild, they may have represented two populations-one with a positive family history and a history of symptoms before enlistment and one without such a background and with symptoms, particularly exhaustion and weakness, apparently precipitated by an event such as an acute infection. ${ }^{28}$

At Hampstead J C Meakins and R $M$ Wilson examined the reaction of soldiers with this syndrome to a sudden visual stimulus followed by an "unexpected discharge of a blank cartridge under the examining couch". ${ }^{29}$ Subjects exposed to this singular ordeal developed more rapid respiratory and pulse rates than did the normal soldiers. (It would not be surprising if other physiological and psychological effects resulted, but they were not described.)

In February 1918 in the Lancet Lewis pointed to the screening and rehabilitative value of a graded recreation and exercise programme conducted in the hospital. ${ }^{30}$ Of 558 men discharged over a six month period in 1916 (average follow up of 11 months) approximately half could be returned to some duty capacity. Such a successful programme sounded remarkably easy to accept, especially for men coming from the trenches. Cohn described how the programme included "setting up exercises, marches with the band; there were round games and tennis, golf and cricket; athletic competitions, lectures and picture shows... There were theatricals, often arranged by the men themselves... And there was plenty of music; in one British camp there were two brass bands, an orchestra, a mandolin, and a banjo club."7 Lewis proposed that a systematic course of exercise be made available in all large military hospitals, a recommendation strongly endorsed by $\mathrm{Sir}$ William Osler ${ }^{31}$ and Sir James Mackenzie. ${ }^{11}$

Lewis summarised his experience in a 144 page monograph published in 1919 entitled "The soldier's heart and the effort syndrome". ${ }^{12} \mathrm{He}$ considered that such a rubric encompassed six subgroups-those with a constitutional nervous or physical weakness, some exposed to extraordinarily unfavourable conditions of work and sleep, those convalescent from acute infectious illnesses, a few with as yet unrecognised infection, a small group recovering from gas poisoning, and another small group with unrecognised heart disease. He considered it not remarkable that some men developed symptoms under wartime stresses, and pointed out that the syndrome was also found in civilian life. He emphasised the universality of the symptom breathlessness (only rarely found at rest), which he considered was probably related to acid-base alterations in the blood. Fatigue, he noted, was also universal as a 
complaint and half of the patients had vague left chest distress with or after effort, with at times hyperaesthesia of the skin or muscles of the chest wall. Palpitation was also very frequent, and there was occasional fainting and some giddiness. He did not agree with Hartshorne and Maclean that this syndrome represented heart strain. He did not find that consumption of alcohol or tobacco, or the presence of hyperthyroidism, were aetiological factors (patients with effort syndrome used less tobacco and alcohol than soldiers with gunshot wounds), nor did he find evidence for a primary defect of the nervous system. He concluded that the dominant aetiological factor in the clinical histories of soldiers complaining of the "effort syndrome" was "infection of one kind or another". In his emphasis on the role of infection, he agreed with Sir James Mackenzie. He encouraged the use of a hygienic regimen including outdoor activities, and of reassurance, and emphasised that bed rest was harmful.

After the armistice in 1918, Lewis assisted the British Ministry of Pensions in its assessment of cases of cardiovascular disability. An outpatient clinic was established at University College Hospital in London, and Parkinson was placed in charge of beds for convalescent cases at the Ministry of Pensions hospital at Orpington. (Brief summaries of the contributions of Lewis and his group during and immediately after the first world war may be found in the annual reports of the Medical Research Committee, 1914-1915 to 1919-1920, published in London by His Majesty's Stationery Office.)

In 1925 Dr Ronald T Grant, who was associated with Lewis, published a five year follow-up of 665 cases of "effort syndrome" seen at the Hampstead and Colchester Military Heart Hospitals during the years 1916-18 and who subsequently lived in the London area. ${ }^{32} \mathrm{He}$ traced over $90 \%$ of the men. Only $15 \%$ seemed to have recovered completely but the overall death rate in the group was not remarkable, although many of the men had developed pulmonary tuberculosis. He reasoned that incipient cardiac disease was not a factor in the syndrome.

Meanwhile, on the other side of the Atlantic in Lakewood, New Jersey, at the United States Army General Hospital No 9, a more modest wartime investigative effort was initiated. Dr Francis Peabody with Dr Clough, Dr Sturgis, Dr Wearn, and Dr Tompkins reported that 65 soldiers with the "constitutionally inferior" type of the syndrome showed an abnormal rise in systolic blood pressure or pulse rate or both in response to an intramuscular injection of adrenaline. ${ }^{33}$ The same group without Peabody and Clough also administered an injection of atropine to these soldiers and noted that the rebound increase in pulse rate after an initial slowing was greater in the patients than in the control subjects. ${ }^{34}$ Adams and Sturgis found little evidence of a reduced vital capacity in the men, ${ }^{35}$ nor could they confirm the 1916 view of Lewis and his colleagues ${ }^{21}$ of any abnormality in the carbon dioxide combining capacity of the blood and in acid-base balance.

A comprehensive report from the American side was prepared in 1919 by Dr Alfred Cohn of Rockefeller University, based both on his clinical experience in England at the Military Hospital at Colchester and in the hospitals of the American Expeditionary Force. ${ }^{7} \mathrm{He}$ reasoned that "the heart in convalescence after acute infectious disease and the Irritable Heart are probably not the same thing" and vigorously proposed that "this symptom complex is neurotic". He minimised but did not discard the importance of constitutional inferiority, writing that "taking constitutional predisposition into account is essential, but as a complete account of failure, it appears to be inadequate." He ended his paper with the conviction that "the disorder is essentially a neurosis, depending upon anxiety and fear; that it is removed by the disappearance of the inciting cause and that it is cured by measures designed to influence the neurotic state."

Neuhof, also writing in 1919 on the topic "The Irritable Heart in General Practice," believed that "the soldier's irritable heart is no new complex, but is the same syndrome seen in civil life, intensified and multiplied by training and war conditions."36 He believed that "some great emotion, fright, dread, shock, is usually the directly antecedent cause of the outbreak of the cardiac symptoms. Reflex excitation from the gastrointestinal tract is the next most frequent." The fundamental process in his view was "hyperexcitation of the sympathetic nervous system".

Dr Paul Dudley White of Boston had received a letter from Dr Alfred Cohn dated 17 May 1917 suggesting that he become a member of the American contingent destined to go to England to work under Thomas Lewis at Hampstead and Colchester. Paul White, having been trained by Lewis, was clearly interested in the proposal but found that he, as a member of the United States Army Medical Corps Reserve, would not be released from his commitments to the Massachusetts General Base Hospital No 6 . Indeed he was placed on active military service on 24 May 1917, only seven days after the date of Cohn's letter soliciting his participation. Paul White had visited the Hampstead Military Hospital on 29 August 1916 and was familiar with British interest in the subject.

Paul White's first publication in this area came after the war in 1920 when he pointed out that, since returning to civilian life, he had seen in six or eight 
weeks 12 young patients with "effort syndrome". 37 This was the first scientific paper to emphasise how common this problem was in civilian practice, and it was succeeded in 1934 by a more comprehensive discussion..$^{13}$ Most of his patients were women, their symptoms were typical, there was no evidence of organic heart disease, and he underscored the importance of correct diagnosis to avoid unnecessary invalidism. He did not support the views of Lewis and Mackenzie of an infectious or bacterial toxic aetiology for most cases. Here at last was an opportunity to consider the syndrome away from the unusual and often highly unfavourable conditions of wartime with their prevalence of respiratory and other infections, abnormal living conditions, uncertain diets, and fear of imminent death. Subsequently over the next 30 years he and his associates (especially Mandel E Cohen, and others including Edwin O Wheeler, Henry B Craig, William P Chapman, Stanley Cobb, Jacques Carlotti, and Eleanor W Reed) produced a series of reports that explored many facets of this puzzling condition. They used the term "neurocirculatory asthenia", which had been preferred by the United States investigators at the end of the first world war.

Cohen and White reported that $2-4 \%$ of the population had this disorder. The mean age of onset was about 25 years. ${ }^{38}$ The disorder affected twice as many women as men, often occurring in successive generations in the same family. Unlike most earlier investigators they called attention to the chronic presence of sighing respirations, the complaint of smothering sensations (especially in crowds), and to the sign of a flushed face and neck; as well as to brisk patellar and Achilles deep tendon reflexes. In a 20 year follow up of 173 patients, over $70 \%$ continued to have some symptoms, but only $15 \%$ had important disability. Symptoms tended to increase with muscular effort, unusual emotion-provoking situations, disagreeable thoughts, and exposure to crowds, but two thirds of the patients could identify no stimulus. Painful stimuli such as heat and a tight sphygmomanometer cuff produced abnormal responses in subjects with neurocirculatory asthenia but not in controls. Patients could not continue as long as control subjects with moderate muscular effort, including running on a treadmill or stepping up and down. They also showed higher pulse and respiratory rates and blood lactate concentrations with exercise than the controls, and pulmonary ventilation was higher but oxygen consumption was the same. These observations coincided with those of the British workers Jones and Scarisbrick, published in $1946 .^{39}$ Rebreathing a mixture containing increased amounts of carbon dioxide often reproduced the symptoms. The symptoms of neurocirculatory asthenia were considered not to be identical with those of fear alone.

In 1958, Kannel et al reviewed the resting electrocardiogram of 203 individuals in the Framingham study considered to have neurocirculatory asthenia and concluded that no electrocardiographic abnormalities were characteristic of this syndrome, ${ }^{40}$ a finding also reported by others.

Paul White and his group concluded that the cause of the condition was unknown and that simple reassurance and observation over time were the most effective therapeutic measures. In their last publication in 1972, Cohen and White additionally suggested that the syndrome might present in two forms-a mild disorder called neurocirculatory asthenia, and a severe illness that was actually manic depressive disease presenting at time with cardiovascular, respiratory, and fatigue symptoms in addition to other complaints. ${ }^{41}$

These extensive long term studies carried out under both peacetime and wartime (second world war) conditions in civilian and military populations give valuable information on many aspects of the problem. Most important of all, they drew attention to neurocirculatory asthenia in the daily practice of cardiology.

In the midst of these investigations by Paul White's laboratory, a major report on the syndrome was presented by Paul Wood in his three Goulstonian Lectures given to the Royal College of Physicians in London in 1941 during the second world war. ${ }^{42}$ Paul Wood flatly stated that he no longer considered that the cause and mechanism were unknown. His was an extensive review of published reports with observations of his own. In his study of 200 military cases, the symptoms in order of frequency were breathlessness $(93 \%)$, palpitation $(89 \%)$, fatigue $(88 \%)$, sweats $(80 \%)$, nervousness $(80 \%)$, dizziness $(78 \%)$, and left chest pain $(78 \%)$. Only $24 \%$ of the subjects could hold their breaths for 30 seconds or more, sweat was visible on the palms in $67 \%$, and $48 \%$ appeared nervous. He considered that the left chest pain might have several explanations including a functional disturbance of the respiratory muscles, strain of the thoracic muscles, or "minimum trauma from the overacting heart of cardiac neurosis." He also commented on raised resting heart rates, sweating of the palms, soles, and axillae, and hyperventilation after forced breathing (but he did not believe that hyperventilation was responsible for the symptoms and signs). He considered that $\mathrm{Da}$ Costa's syndrome should be regarded "as an emotional reactive pattern peculiar to psychopathic personalities and to subjects of almost any form of psychoneurosis."

Paul Wood's conclusions included the following: 
"The symptoms and signs of Da Costa's syndrome more closely resemble those of emotion, especially fear, than those of effort in the normal subject. The mechanism of somatic manifestations depends on central stimulation, not upon hypersensitivity of the peripheral autonomic 'gear'. This central stimulus is emotional, and is commonly the result of fear. The reaction becomes linked to effort by a variety of devices, which include misinterpretation of emotional symptoms, certain vicious circular patterns, the growth of a conviction that the heart is to blame, consequent fear of sudden death on exertion, conditioning and hysteria. Incapacity tends to be exaggerated consciously or subconsciously in order to protect the individual from further painful emotional experience."

Thus Paul Wood, after wartime experience with the condition, came down squarely on the side of viewing Da Costa's syndrome as a manifestation of emotion, more in keeping with the view of Cohn than that of Mackenzie or Lewis, and unlike that of White and Cohen, who considered that the issue was decidedly more complex.

It was doubtless in part because of Paul Wood's influential views, well spread over three issues of the British Medical Journal in 1941, that during the second world war there was a diminished interest in $\mathrm{Da}$ Costa's syndrome as a medical entity. Many of the cases seem to have been treated by psychiatrists and ended up with various diagnostic labels. In the third edition of his textbook on heart disease, published in 1968, Paul Wood restated his views in accord with this impression:

"It should be understood that there is no essential difference between 'effort syndrome' and 'cardiac neurosis', they are merely clothed differently, the former in battle dress, and latter in nylon. In civil life the condition accounts for 10 to 15 per cent of all cases referred to cardiovascular clinics; it is common in children, and occurs more often in women than in men, the ratio being 3:2. It has a preference for the emotional races, especially the Jews and Italians. In the first world war there were some 60,000 'effort syndrome' casualties in the British forces; in the second a more enlighted view was taken, the majority of these cases receiving appropriate psychiatric labels and management." 43

Friedberg, in the third edition of his text Diseases of the Heart, published in 1966, also expressed a psychiatrically oriented view when he wrote: "The underlying cause appears to be a fundamental ego insecurity arising from psychological problems which began in infancy and childhood". ${ }^{44}$ A more recent (1974) review by Caranasos expresses a similar sentiment. ${ }^{45}$

The past few years have seen two further lines of exploration. The first of these has been the suggestion by some that there is an overlap between neurocirculatory asthenia and mitral valve prolapse, and that both can be considered within a single rubric.

Jeresaty wrote in 1979 that "many of the patients previously described as suffering from $\mathrm{Da}$ Costa's syndrome, soldier's heart, the effort syndrome, and neurocirculatory asthenia would now be classified under the heading of mitral valve prolapse syndrome". ${ }^{46}$ Barlow and Pocock stated in 1984: "We are also aware that some patients diagnosed by us as primary mitral valve prolapse syndrome would be classified by others as neurocirculatory asthenia, $\mathrm{Da}$ Costa's syndrome, non-specific $\mathrm{T}$-wave changes, atypical chest pain syndrome, so-called 'syndrome $\mathrm{X}$ ' or similar conditions". ${ }^{47}$ It is important that Barlow and Pocock spoke only of "some patients". Wooley noted in 1985 and also earlier how "As knowledge and technology progressed, the pathway from neurocirculatory asthenia would eventually lead to anxiety neuroses of World War II, systolic click and late systolic murmur syndrome of the 1960 's, and the mitral valve prolapse syndrome, panic disorders, and autonomic dysfunction states of the 1970's and 1980's". ${ }^{48}$

The fact that the disorders referred to all share uncertain aetiology, vague symptoms, no means of specific identification by laboratory means, and are usually unresponsive to conventional treatment should not in itself justify creating a new umbrella label. Because both mitral valve prolapse and neurocirculatory asthenia are common some individuals are likely to show evidence of both conditions.

It is important to emphasise, as have nearly all of those physicians who studied the problem carefully, that all patients with neurocirculatory asthenia complain of undue shortness of breath on effort and often at rest, approximately $90 \%$ have palpitation and fatigue, and approximately $50-75 \%$ report chest pain. This is not what has usually been reported with the mitral valve prolapse syndrome. It is apparent that most young patients with mitral valve prolapse syndrome have no symptoms at all if the condition is detected on a screening examination; and even among those seen in the usual clinic (office) setting, which concentrates those patients with symptoms, symptoms are much less common than in neurocirculatory asthenia. Jeresaty reported chest pain in $61 \%$, fatigue in $42 \%$, and dyspnoea in only $38 \%$ of 100 cases of mitral valve prolapse. ${ }^{46}$ Barlow et al in their original 1968 description of 63 patients with systolic murmurs and in some cases nonejection clicks, also described tiredness, palpitation, breathlessness, or chest pain in only $39(62 \%) .{ }^{49}$

Leatham and Brigden wrote firmly in 1980 in an 
article entitled "Mild Mitral Regurgitation and the Mitral Prolapse Fiasco" that "isolated disease of the mitral valve causing mild or moderate reflux seldom causes symptoms other than those of iatrogenic anxiety." 50 Leor and Markiewicz from the Rambam Medical Center in Haifa, Israel, used auscultation and echocardiography to study 42 young soldiers with neurocirculatory asthenia; they concluded that "mitral prolapse and neurocirculatory asthenia do not appear to be related". ${ }^{51}$ Silverman et al studied 68 patients seen in private practice, 57 of whom were women, in whom mitral valve prolapse was diagnosed by echocardiography. ${ }^{52}$ While they concluded that the symptoms of neurocirculatory asthenia were more common in patients with mitral valve prolapse than in an age and sex matched control population, only 34 of the 68 complained of dyspnoea (as did 19 of the controls) and fatigue. Symptoms related to effort were not mentioned. Retchin et al investigated 274 outpatients and suggested that "symptoms and dysfunction are not related to the presence of mitral valve prolapse by echocardiography". ${ }^{53}$ Devereux et al in another large study concluded that "nonanginal chest pain, dyspnoea, panic attacks and electrocardiographic abnormalities have appeared to be associated with mitral valve prolapse because of ascertainment bias and an erroneous classification of differences between men and women as being due to mitral valve prolapse". ${ }^{54}$

It seems best to keep neurocirculatory asthenia and mitral valve prolapse as separate categories for the time being because they do not have sufficient similarities to justify a single label. This does not mean that a few individuals do not demonstrate evidence of both conditions. The hyperkinetic heart syndrome also appears to be different from neurocirculatory asthenia and should also be considered as a separate entity. ${ }^{556}$

The second line of investigation has been the treatment of neurocirculatory asthenia with $\beta$ blocking agents. Here, much as in the mitral valve prolapse story, there has been a modest amount of smoke but not much fire. Caranasos in 1974 summarised the situation as follows: "Recently propranolol has been found effective in diminishing or even abolishing the cardiovascular signs and symptoms of 'NCA', but the psychic symptoms are unaffected". ${ }^{45}$ Rimon et al in an unimpressive, uncontrolled study published in 1979 in the Israel Annals of Psychiatry, listed many non-specific symptoms such as depression, palpitation, difficulty in falling asleep, tension headache, etc said to have been improved in 36 patients with neurocirculatory asthenia as result of treatment with propranolol. ${ }^{57}$ No conclusions are justified from this evidence.

In 1974 Wolf et al of Hadassah University Hospi- tal in Jerusalem treated five men and five women with neurocirculatory asthenia with intravenous propranolol. In all of them there was improvement in ST-T abnormalities in the resting electrocardiograms. ${ }^{58}$ Here again, no definite conclusions can be drawn from such observations. Indeed, the whole area of the treatment of disorders associated with anxiety with $\beta$ blocking drugs appears controversial. $^{59}$

$\mathrm{Da}$ Costa's syndrome or neurocirculatory asthenia has been a common condition in the experience of many seasoned clinicians. Past studies have shown that it has often had a familial background, has occurred in both civilian and military life, and especially in women, has had certain identifiable symptoms, no specific signs, and few demonstrable physiological and psychological abnormalities. There has been no, or a poor, therapeutic response to rest, and no convincing evidence of benefit from diet, surgery (adrenal gland denervation was practised by Crile in the $1930 \mathrm{~s}^{6061}$ ), or drugs. A programme of reassurance, exercise, and physical fitness has been of value.

It is important to be able to recognise the condition irrespective of the label used. The diagnosis is usually not difficult for an interested reasonably intelligent physician. Be alert for the younger patient with unexplained shortness of breath, easy fatigue, and a history of palpitation and atypical chest pain, who sighs frequently during the course of the conversation. All too many patients with this syndrome, mainly women, are still mistakenly labelled as having organic heart disease including angina pectoris, and this leads to the additional problem of an unnecessary cardiac neurosis. (Not all patients with neurocirculatory asthenia have a cardiac neurosis and not all patients with a cardiac neurosis have neurocirculatory asthenia.) It is essential to be able to reassure the patient with neurocirculatory asthenia, to understand that the condition may be life long with remissions and exacerbations, and to appreciate that it may to some extent limit physically strenuous effort. Finally, it does not appear profitable at this time to attempt to combine neurocirculatory asthenia and mitral valve prolapse within a single diagnostic category.

\section{References}

1 Hartshorne H. On heart disease in the army. Am J Med Sci 1864;48:89-92.

2 Stillé A. Address before the Philadelphia County Medical Society. Philadelphia: Collins, Printer, 1863:18-19.

3 Maclean WC. Diseases of the heart in the British Army: the cause and the remedy. $\mathrm{Br} M e d J 1867 ; \mathbf{i}: 161-4$.

$4 \mathrm{Da}$ Costa JM. On irritable heart: a clinical study of a form of functional cardiac disorder and its con- 
sequences. Am J Med Sci 1871;61(No. 121):17-52.

5 Wooley CF. Jacob Mendez Da Costa: medical teacher, clinician and clinical investigator. Am J Cardiol 1982;50:1145-8.

6 Howell JD. Soldier's heart: the redefinition of heart disease and specialty formation in early twentieth century Great Britain. Med Hist 1985;(suppl 5):34-52.

7 Cohn AE. The cardiac phase of the war neuroses. Am J Med Sci 1919;158:453-70.

8 Goldscheider A. Aufgaben und Probleme der inneren Medizin in Kriege Berliner. Klin Wochenschr 1915;52:1130-3, 1157-9.

9 Revue Analytique. Arch Mal Coeur 1916;9:355-65.

10 Cotton T, Lewis T, Thiele FH. A note on the "irritable heart" of soldiers. Br Med J 1915;ii:722.

11 Mackenzie J. The soldier's heart. $B r$ Med J 1916;i:117-9.

12 Lewis $\mathrm{T}$. The soldier's heart and the effort syndrome. New York: Paul B Hoeber, 1919:1-103.

13 Craig HR, White PD. Etiology and symptoms of neurocirculatory asthenia. Arch Intern Med 1934;53:645-8.

14 Pickering GW. In memoriam. Clin Sci 1948;6:3-11.

15 Mackenzie J. The soldier's heart and war neurosis. $\mathrm{Br}$ Med J 1920;i:491-4, 530-4.

16 Parkinson J. The cardiac disabilities of soldiers on active service. Lancet 1916;ii:133-8.

17 Cotton TF, Rapport DL, Lewis T. After effects of exercise on pulse rate and systolic blood pressure in cases of "irritable heart". Heart 1917;6:269-84.

18 Meakins JC, Gunson EB. Orthodiagraphic observations on the size of the heart in cases of so-called "irritable heart". Heart 1918;7:1-16.

19 Levine SA, Wilson FN. Observations on the vital capacity of the lungs in cases of "irritable heart." Heart 1919;7:53-61.

20 Meakins JC, Gunson EB. The occurrence of hyperalgesia in the "irritable heart of soldiers". Heart 1917;6:343-53.

21 Lewis T, Cotton TF, Barcroft J, et al. Breathlessness in soldiers suffering from irritable heart. $\mathrm{Br} \mathrm{Med} J$ 1916;ii:517-9.

22 Wilson FN, Levine SA, Edgar AB. The bicarbonate concentration of the blood plasma in cases of "irritable heart." Heart 1919;7:62-4.

23 Parkinson J. Digitalis in soldiers with cardiac symptoms and a frequent pulse. Heart 1917;6:321-36.

24 Cotton TF, Rapport DL, Lewis T. Observation upon atropine. Heart 1917;6:293-8.

25 Cotton TF, Slade JG, Lewis T. Observations upon pilocarpine nitrate. Heart 1917;6:299-310.

26 Cotton TF, Slade JG, Lewis T. Observations upon amyl nitrite. Heart 1917;6:311-5.

27 Parkinson J, Drury AN. The P-R interval before and after exercise in cases of "soldier's heart". Heart 1917;6:337-42.

28 Oppenheimer BS, Rothschild MA. The psychoneurotic factor in the "irritable heart" of soldiers. $\mathrm{Br}$ Med J 1918;ii:29-31.

29 Meakins JC, Wilson RM. The effect of certain sensory stimulations on respiratory and heart rate in cases of so-called "irritable heart". Heart 1918;7:17-22.

30 Lewis T. Observations upon prognosis, with special reference to the condition described as the "irritable heart of soldiers." Lancet 1918;i:181-3.

31 Osler W. Graduated exercise in prognosis. [Letter]. Lancet 1918;1:231.

32 Grant RT. Observations on the after-histories of men suffering from the effort syndrome. Heart 1925;12:121-42.

33 Peabody FW, Clough HD, Sturgis CC, Wearn JT, Tompkins EH. Effects of the injection of epinephrin in soldiers with "irritable heart." JAMA 1918;71:1912-3.

34 Sturgis CC, Wearn JT, Tompkins EH. Effects of the injection of atropin on the pulse-rate, blood-pressure and basal metabolism in cases of "effort syndrome." Am J Med Sci 1919;158:496-502.

35 Adams FD, Sturgis CC. Note on the vital capacity of the lungs and the carbon dioxide combining capacity of the blood in cases of "effort syndrome." $\mathrm{Am} \mathrm{J} \mathrm{Med}$ Sci 1919;158:816-8.

36 Neuhof S. The irritable heart in general practice. Arch Intern Med 1919;24:51-64.

37 White PD. The diagnosis of heart disease in young people. JAMA 1920;74:580-2.

38 Cohen ME, White PD. Life situations, emotions, and neurocirculatory asthenia (anxiety neurosis, neurasthenia, effort syndrome). Psychosom Med 1951;13:335-57.

39 Jones M, Scarisbrick R. Effect of exercise on soldiers with neurocirculatory asthenia. Psychosom Med 1946;8:188-92.

40 Kannel WB, Dawber TR, Cohen ME. The electrocardiogram in neurocirculatory asthenia (anxiety neurosis or neurasthenia): a study of 203 neurocirculatory asthenia patients and 757 healthy controls in the Framingham study. Ann Intern Med 1958;49:1351-60.

41 Cohen ME, White PD. Neurocirculatory asthenia: 1972 concept. Milit Med 1972;137:142-4.

42 Wood P. Da Costa's syndrome (or effort syndrome). $\mathrm{Br}$ Med J 1941;i:767-72, 805-11, 845-51.

43 Wood P. Diseases of the heart and circulation. 3rd ed. London: Eyre and Spottiswoode, 1968:1074-5.

44 Friedberg CK. Diseases of the heart. 3rd ed. Philadelphia: WB Saunders, 1966:1721.

45 Caranasos GJ. Neurocirculatory asthenia. In: Eliot RS, ed. Stress and the heart. Mt Kisco, New York: Futura, 1974:235-8.

46 Jeresaty RM. Mitral valve prolapse. New York: Raven Press, 1979:44.

47 Barlow JB, Pocock WA. The mitral valve prolapse enigma-two decades later. Mod Concepts Cardiovasc Dis 1984;53:13-7.

48 Wooley CF. From irritable heart to mitral valve prolapse: British Army medical reports, 1860 to 1870. Am J Cardiol 1985;55:1107-9.

49 Barlow JB, Bosman CK, Pocock WA, Marchand P. Late systolic murmurs and non-ejection ("mid-late") systolic clicks. An analysis of 90 patients. $\mathrm{Br}$ Heart $J$ 1968;30:203-18.

50 Leatham A, Brigden W. Mild mitral regurgitation and 
the mitral prolapse fiasco. Am Heart J 1980;99:659-64.

51 Leor R, Markiewicz W. Neurocirculatory asthenia and mitral valve prolapse-two unrelated entities? Isr $J$ Med Sci 1981;17:1137-9.

52 Silverman BD, Berry JN, Flowers C. Mitral valve prolapse: its symptom complex and its association with $\mathrm{Da}$ Costa's syndrome. South Med J 1984;77:27-9.

53 Retchin SM, Fletcher RH, Earp J, Lamson N, Waugh RA. Mitral valve prolapse. Disease or illness. Arch Intern Med 1986;146:1081-4.

54 Devereux RB, Kramer-Fox R, Brown WT, et al. Relation between clinical features of the mitral valve prolapse syndrome and echocardiographically documented mitral valve prolapse. J Am Coll Cardiol 1986;8:763-72.

55 Gorlin $\mathrm{R}$. The hyperkinetic heart syndrome. JAMA 1962;182:823-9.

56 Gillum RF, Teicholz LE, Herman MV, Gorlin R. The idiopathic hyperkinetic heart syndrome: clinical course and long-term prognosis. Am Heart J 1981;102:728-34.

57 Rimon R, Kampman R, Viukari M. Propranolol in the treatment of neurocirculatory asthenia-an open pilot study. Isr Ann Psychiatry 1979;17:144-8.

58 Wolf E, Braun K, Stern S. Effects of beta-receptor blocking agents propranolol and practolol on ST-T changes in neurocirculatory asthenia. Br Heart $J$ 1974;36:872-9.

59 Hollister LE. Clinical pharmacology of psychotherapeutic drugs. New York: Churchill Livingstone, 1983:38.

60 Crile GW. Recurrent hyperthyroidism, neurocirculatory asthenia and peptic ulcer. JAMA 1931;97:1616-8.

61 Crile G. Denervation of the adrenal glands for neurocirculatory asthenia. Surg Gynecol Obstet 1932;54:294-8. 